\title{
Changes in spirometric parameters with position in asymptomatic Egyptian young males with central obesity
}

\author{
Nermeen A. Abd-Elaleem, ${ }^{1}$ Sherif A. A. Mohamed, ${ }^{1}$ Wael M. Wagdy, ${ }^{2}$ Reham A. Abd-Elaleem, ${ }^{3}$ \\ Azza S. Abdelhafeez, ${ }^{4}$ Hassan A. Bayoumi ${ }^{1}$ \\ ${ }^{1}$ Department of Chest Diseases and Tuberculosis, Faculty of Medicine, Assiut University, Assiut \\ ${ }^{2}$ Department of Radiology, Faculty of Medicine, South Valley University, Qena \\ ${ }^{3}$ Department of Radiology, Faculty of Medicine, Assiut University, Assiut \\ ${ }^{4}$ Department of Medical Physiology, Faculty of Medicine, Assiut University, Assiut, Egypt
}

\begin{abstract}
Background: Central obesity is a chronic condition that can contribute to impairments in lung functions. Body position is an important technique that effectively restores and increases lung functions. We aimed to address the possible changes in spirometric parameters in asymptomatic overweight individuals with central obesity with a change in posture from sitting to supine in comparison to normal weight non-obese ones.

Methods: Enrolled subjects were healthy Egyptian males, aged between 20-45 years old, asymptomatic and nonsmokers. They underwent spirometry. The following parameters were measured; forced expiratory volume in one second $\left(\mathrm{FEV}_{1}\right)$, forced vital capacity $(\mathrm{FVC}), \mathrm{FEV}_{1} / \mathrm{FVC}$ ratio, and forced expiratory flow (FEF) 25-75\%. They were classified into overweight with central obesity $(n=40)$ and healthy control $(n=40)$ groups based on their body mass index (BMI), weight-hip ratio (WHR), and waist circumference (WC). Spirometric parameters were compared between the 2 groups and in both setting and supine positions.

Results: The central obesity group showed significantly lower all spirometric parameters in comparison to the control one. All measured spirometric parameters had a significant reduction with supine position. There were negative correlations between both the WC and WHR and spirometric parameters.

Conclusion: In this study of young Egyptian males, individuals with central obesity had reduced spirometric parameters in comparison to healthy ones. Change in position from sitting to supine has significant effects on spirometric parameters in both healthy middle age males with normal weight and those with overweight and central obesity. These results could have important clinical implications.
\end{abstract}

Key words: Obesity; position; males; central; spirometry; healthy; asymptomatic; changes.

Correspondence: Dr. Sherif A. A. Mohamed, Associate Professor of Pulmonary Medicine, Department of Chest Diseases and Tuberculosis, Faculty of Medicine, Assiut University, 71516 Assiut, Egypt.

Tel. +20.88.2413713,+20.966.538618846 - Fax:+20.88.241333327. E-mail: saawm220@gmail.com

Contributions: NAA, SAAM, HAB, contributed to the draft of the submitted article, revised it critically for important content, and made substantial contributions to conception and design, as well as data acquisition, analysis, and interpretation; SAAM, WMW, RAA, ASA, contributed to the draft of the submitted article and made substantial contributions to acquisition, analysis, and interpretation of clinical and physiological data. All authors have provided approval of the manuscript to be published and have agreed to be accountable for all aspects of the work in ensuring that questions related to the accuracy or integrity of any part of the work are appropriately investigated and resolved.

Conflict of interest: The authors have no competing interests.

Funding: This research did not receive any specific grant from funding agencies in the public, commercial, or not-for-profit sectors.

Availability of data and materials: The datasets used and/or analyzed during the current study are available from the corresponding author on reasonable request.

Ethics approval and consent to participate: The study was approved by the Ethical Committee of the Faculty of Medicine, Assiut University (Approval number 5882). All subjects were informed about the research objectives and methods and written consent was obtained prior to data collection.

Consent for publication: Not applicable. 


\section{Introduction}

The World Health Organization (WHO) defines adult obesity by a body mass index (BMI) greater than or equal to $30 \mathrm{~kg} / \mathrm{m}^{2}$ and overweight as a BMI over $25 \mathrm{~kg} / \mathrm{m}^{2}$ [1]. Obesity has become a global health issue $[2,3]$. Obesity, especially abdominal obesity, is related to cardiovascular disease, metabolic syndrome, and risk factors of all-cause mortality [4-6]. Central (also called abdominal or android) obesity is defined as increased fat deposition in the thorax, abdomen, and visceral organs, with apple-like body shape in males [7]. The waist circumference (WC) and the waist-to-hip ratio (WHR) had become the easiest accepted measurements for abdominal obesity $[3,8,9]$. The mechanical properties of the lungs and chest wall are much affected in obesity. Excessive fat accumulation in the thoracic-abdominal region restricts the chest wall expansion and diaphragmatic muscle contraction, lengthens abdominal muscles, reduces the upper airway calibre, modifies airway configuration, and increases in intra-abdominal pressure [1014]. It is well-known that the lung function can be affected by several factors such as age, sex, physical activity, and body positions [10-14]. Among these factors, body position changes can be used as an intervention to improve lung function [15-17], given the direct effect of body position on chest wall motion, respiratory muscles performance, and breathing patterns [15-18], particularly in individuals with obesity [15-17]. Several body positions (such as sitting, Fowler's, side lying, supine, and prone positions) have been shown to affect lung function and help in preserving lung performance and reducing the risk of complications [18-20].

Several studies have focused on the cardiovascular effects of obesity, yet few ones addressed changes in spirometric parameters due to obesity $[15,17,21]$. Furthermore, studying the effects of both abdominal obesity as a specific type of obesity and multiple body positions on lung function in the same group of individuals is not well understood yet.

Therefore, the current study aimed to address the possible changes in spirometric parameters in asymptomatic overweight individuals with central obesity with a change in posture from sitting to supine in comparison to normal weight non-obese ones.

\section{Materials and Methods}

\section{Study population}

The subjects were recruited from the general population. The inclusion criteria included male, aged between 20-45 years old, asymptomatic and free from any underlying health conditions particularly cardiovascular or respiratory disease and willing to undergo the study. All smokers were excluded. The participant had no contraindication to spirometry. All subjects were informed about the research objectives and methods and written consent was obtained prior to data collection. Ethical approval was obtained from the Ethical Committee of the Faculty of Medicine, Assiut University, Egypt (Approval number 5882).

The subjects were classified into overweight with central obesity $(n=40)$ and healthy control $(n=40)$ groups based on their body mass index (BMI), weight-hip ratio (WHR), and waist circumference (WC). The healthy control group had BMI: $18.5-<25 \mathrm{~kg} / \mathrm{m}^{2}$ while the overweight one had BMI $25-<30 \mathrm{~kg} / \mathrm{m}^{2}$ ) [22]. Pre-specified cut-off points for defining central obesity in men is WHR $>0.9$ $[23,24]$ and $\mathrm{WC}>94 \mathrm{~cm}[25,26]$.

\section{Study methods}

\section{Spirometry}

Standard spirometry was performed in all individuals by mean of a fully equipped computerized system (Quark PFTs ergo, P/N Co9035-12-99; Cosmed Srl, Albano Laziale, RM, Italy). All pulmonary function tests were carried out at a fixed time of the day in the morning (9.00-12.00 hours) to minimize diurnal variation. Each subject was informed about the whole maneuver and was encouraged to practice it before testing. The apparatus was calibrated daily and operated within the ambient temperature range of $20-25^{\circ} \mathrm{C}$. The tests were repeated three times after adequate rest. The best result of three reproducible tests was taken. The subjects were asked to perform the forced expiration maneuver in the sitting position first. The same procedure was repeated after $15 \mathrm{~min}$ interval in supine position. Three trials with FVC within $5 \%$ of each other were selected for analysis in both positions. Three minutes intervals were given before each trial. Acceptability and reproducibility of the graphs were evaluated well before accepting the result. The data collected included forced expiratory volume in one second $\left(\mathrm{FEV}_{1}\right)$, forced vital capacity $(\mathrm{FVC}), \mathrm{FEV}_{1} / \mathrm{FVC}$ ratio and forced expiratory flow (FEF) $25 \%-75 \%$ according to the guidelines of the American Thoracic Society and European Respiratory Society [27].

\section{Anthropometric measurements}

Weight and height were measured with subjects wearing lightweight clothing and barefoot by using a stadiometer and then calculating BMI (it is the ratio of weight in kilograms to the square of height in meters, expressed in units of $\mathrm{kg} / \mathrm{m}^{2}$ ). By tape, we measured waist circumference (WC): the distance at midway level between the lower margin of the last rib and the iliac crest, just above belly button. Then we measured hip circumference (HC): the distance around the largest part of hips at the widest part of buttocks without compressing the soft tissues. Finally, we calculated waist-to-hip ratio (WHR) by dividing waist circumference by hip circumference.

\section{Body positions}

Participants performed two body positions including sitting with back support, and supine positions. Vital signs (heart rate, blood pressure, respiratory rate, and oxygen saturation) were recorded during each position to ensure that they remained stable. Sitting position was to sit upright with neck and chest aligned and straight. A rest period was 15 min before each position change. Supine position was to lie flat on the bed, head and neck in neutral position and supported by a pillow. Figure 1 shows flow chart of the study.

\section{Statistical analysis}

Parameters were expressed as mean \pm SD. An independent samples $t$-test used to assess the difference between the means of the two groups. Paired $t$-test was used to compare the changes in the same group but different positions. Correlation between anthropometric data spirometric parameters was carried out using Spearman's correlation test. A $\mathrm{p}<0.05$ was considered statistically significant. The SPSS (Statistical Package for Social Science) software version 25 was used for statistical analysis.

\section{Results}

\section{Demographic characteristics}

The baseline characteristics are shown in Table 1. There were statistically significant differences in weight, height BMI, WC, WHR, systolic blood pressure, and respiratory rate between the control and central obesity groups. 


\section{Differences in spirometric parameters between groups in 2 positions}

The differences between control and central obesity groups in spirometric parameters in 2 positions are shown in Table 2. Characteristically, the central obesity group showed significantly lower all spirometric parameters $\left(\mathrm{FEV}_{1}, \mathrm{FVC}, \mathrm{FEV}_{1} / \mathrm{FVC}\right.$, and FEF25-75\%).

\section{Effects of change in position}

The effects of changing position from sitting to supine in the control and central obesity groups are shown in Tables 3 and 4, respectively. All measured spirometric parameters had a statistically significant reduction with supine position.

\section{Correlations between the anthropometric and supine spirometric parameters}

Table 5 shows significantly negative correlations between WC and spirometric parameters as well as between WHR and spirometric parameters.

\section{Discussion}

Although obesity is common in the community, still it is a modifiable risk factor for a large number of disorders that increase morbidity and mortality in obese subjects. The tested hypothesis of this study was the impact of central obesity in different body positions on spirometric parameters among young males.

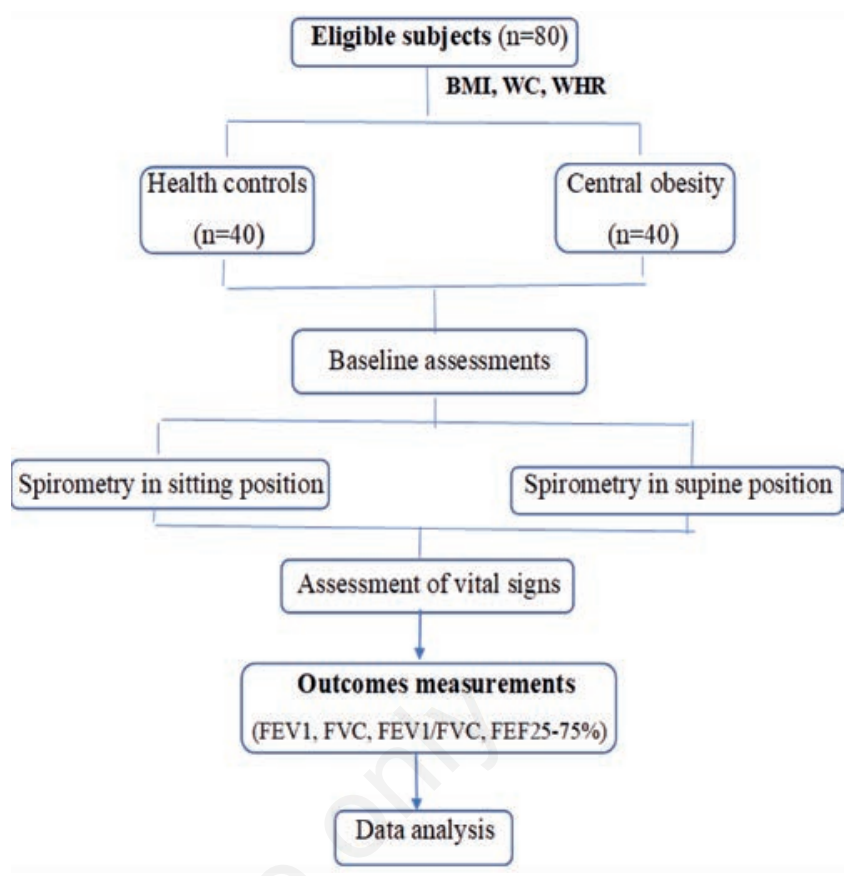

Figure 1. Flow chart of the study. BMI, body mass index; WC, waist circumference; WHR, waist-hip ratio; $\mathrm{FEV}_{1}$, forced expiratory volume in one second; FVC, forced vital capacity; FEF. forced expiratory flow.

Table 1. Demographic characteristics of the study subjects.

\begin{tabular}{lccc} 
& Control group $(\mathbf{n = 4 0})$ & Central obesity group (n=40) & p \\
Age (years) & $32.37 \pm 5.61$ & $32.73 \pm 5.99$ & 0.808 \\
Weight $(\mathrm{kg})$ & $68.4 \pm 3.74$ & $78.2 \pm 4.35$ & 0.000 \\
\hline Height $(\mathrm{cm})$ & $170.47 \pm 3.46$ & $170.8 \pm 3.03$ & 0.693 \\
BMI $\left(\mathrm{kg} / \mathrm{m}^{2}\right)$ & $23.53 \pm 0.88$ & $26.79 \pm 0.91$ & 0.000 \\
Waist circumference (WC), $\mathrm{cm}$ & $81.3 \pm 3.87$ & $96.8 \pm 3.01$ & 0.000 \\
Waisthip ratio (WHR) & $0.85 \pm 0.03$ & $0.95 \pm 0.04$ & 0.000 \\
Systolic blood pressure $(\mathrm{mmHg})$ & $111.67 \pm 3.02$ & $116.20 \pm 4.09$ & 0.000 \\
Heart rate & $81.30 \pm 4.89$ & $84.87 \pm 7.57$ & 0.034 \\
Respiratory rate & $14.03 \pm 1.09$ & $15.63 \pm 1.13$ & 0.000 \\
$\mathrm{SpO}_{2}$ & $97.63 \pm 0.76$ & $97.5 \pm 0.86$ & 0.529 \\
\hline
\end{tabular}

Data are expressed as mean $\pm \mathrm{SD} ; \mathrm{SpO}_{2}$, oxygen saturation.

Table 2. Differences in spirometric parameters between control and central obesity groups in 2 positions.

\begin{tabular}{lccc} 
& Control group $(\mathbf{n = 4 0 )}$ & Central obesity group $(\mathbf{n = 4 0 )}$ & p \\
FEV $_{1}$ sitting position & $3.47 \pm 0.19$ & $2.90 \pm 0.28$ & 0.000 \\
FEV $_{1}$ supine position & $3.20 \pm 0.16$ & $2.58 \pm 0.32$ & 0.000 \\
\hline FVC sitting position & $4.20 \pm 0.21$ & $3.64 \pm 0.29$ & 0.000 \\
FVC supine position & $3.98 \pm 0.18$ & $3.35 \pm 0.42$ & 0.000 \\
\hline FEV $_{1} /$ FVC sitting position & $82.91 \pm 3.24$ & $79.81 \pm 5.12$ & 0.007 \\
FEV $_{1} /$ FVC supine position & $80.44 \pm 3.29$ & $76.86 \pm 3.81$ & 0.002 \\
FEF 25-75\% sitting position & $3.83 \pm 0.07$ & $3.74 \pm 0.05$ & 0.000 \\
FEF 25-75\% supine position & $2.91 \pm 0.14$ & $2.68 \pm 0.05$ & 0.000
\end{tabular}

$\mathrm{FEV}_{1}$, forced expiratory volume in one second; FVC, forced vital capacity; FEV/FVC, FEV1/FVC ratio; FEF, forced expiratory flow. 
Characteristically, in comparison to the control group, the central obesity one showed significantly lower all spirometric parameters. Furthermore, all measured spirometric parameters had a significant reduction with supine position.

The significantly lower values of spirometric parameters in central obesity group could be explained by lower respiratory muscle strength in those subjects [15]. Moreover, it was reported that increased BMI leads to narrower airways which explain functional airway changes [28]. Furthermore, prior studies had shown that obese subjects tend to have a small airway collapse in comparable to normal weight subjects $[13,14]$.

On the other hand, our results are not in agreement with those obtained by Al Lawati and Al Atbi [17]. The authors enrolled young Omani males in their study for the effects of obesity on the airflow parameters while changing the posture from sitting to supine position in non-obese, overweight, and obese individuals. However, they found that the difference in airflow parameters with the change in posture from sitting to supine position was not significantly different in obese subjects as compared with non-obese and overweight subjects. They explained the obtained results by small sample size or because of the fixed age group (19-25 years old). Differences between results of the current study and that of $\mathrm{Al}$

Table 3. Effects of change in position in the control group.

\begin{tabular}{lccc} 
& Sitting position & Supine position & p \\
FEV $_{1}$ & $3.48 \pm 0.19$ & $3.21 \pm 0.16$ & 0.000 \\
FVC & $4.20 \pm 0.21$ & $3.99 \pm 0.18$ & 0.000 \\
\hline FEV1/FVC & $82.92 \pm 3.24$ & $80.44 \pm 3.29$ & 0.000 \\
FEF 25-75\% & $2.94 \pm 0.14$ & $3.83 \pm 0.07$ & 0.000 \\
\hline
\end{tabular}

$\mathrm{FEV}_{1}$, forced expiratory volume in one second; $\mathrm{FVC}$, forced vital capacity; $\mathrm{FEV}_{1} / \mathrm{FVC}, \mathrm{FEV}_{1} / \mathrm{FVC}$ ratio; FEF, forced expiratory flow.

Table 4. Effects of change in position in the central obesity group.

\begin{tabular}{lccc} 
& Sitting position & Supine position & p \\
$\mathrm{FEV}_{1}$ & $2.90 \pm 0.28$ & $2.58 \pm 0.32$ & 0.000 \\
$\mathrm{FVC}$ & $3.60 \pm 0.25$ & $3.45 \pm 0.43$ & 0.017 \\
\hline $\mathrm{FEV}_{\mathrm{l}} / \mathrm{FVC}$ & $81.81 \pm 4.09$ & $76.86 \pm 3.82$ & 0.009 \\
$\mathrm{FEF} 25-75 \%$ & $2.68 \pm 0.05$ & $3.73 \pm 0.05$ & 0.000 \\
\hline
\end{tabular}

$\mathrm{FEV}_{1}$, forced expiratory volume in one second; $\mathrm{FVC}$, forced vital capacity; $\mathrm{FEV}_{1} / \mathrm{FVC}, \mathrm{FEV}_{1} / \mathrm{FVC}$ ratio; FEF, forced expiratory flow.

Table 5. Correlations between the anthropometric and supine spirometric parameters.

\begin{tabular}{lcc} 
& $\mathbf{r}$ & $\mathbf{p}$ \\
WHR - FEV $_{1}$ & -0.611 & 0.000 \\
WHR - FVC & -0.611 & 0.000 \\
\hline WHR - FEV $/$ FVC & -0.361 & 0.015 \\
WHR - FEF25-75\% & -0.528 & 0.000 \\
\hline WC - FEV & -0.691 & 0.000 \\
WC - FVC & -0.606 & 0.000 \\
\hline WC - FEV /FVC & -0.463 & 0.001 \\
WC - FEF25-75\% & -0.505 & 0.001
\end{tabular}

WC, waist circumference; WHR, waisthip ratio; $\mathrm{FEV}_{1}$, forced expiratory volume in one second; $\mathrm{FVC}$, forced vital capacity; $\mathrm{FEV}_{1} / \mathrm{FVC}, \mathrm{FEV}_{1} / \mathrm{FVC}$ ratio; FEF, forced expiratory flow.
Lawati and Al Atbi [17] could be attributable to different population phenotypic characteristics and/or methodological analysis.

In a recent study, Peralta and co-workers [21] estimated the lung function trajectories during adulthood from 20-year weight change profiles using data from the population-based European Community Respiratory Health Survey (ECRHS). The 3,673 participants were recruited at age 20-44 years with repeated measurements of weight and lung function $\left(\mathrm{FVC}, \mathrm{FEV}_{1}\right)$ in 3 study waves (1991-93, 1999-2003, 2010-14) until they were 39-67 years of age. The authors concluded that moderate and high weight gain over 20 years was associated with accelerated lung function decline, while weight loss was related to its attenuation. Thus, control of weight gain is important for maintaining good lung function in adult life [21].

Another important finding in this study was that all measured spirometric parameters had a statistically significant reduction with supine position. Even in the control group, all measured spirometric parameters had a statistically significant reduction with supine position. This is in accordance with the results obtained by Patel et al. [29] and Vilke et al. [30], who observed significant reduction in supine position values. These findings could be explained by the effect of abdominal content and intraabdominal pressure on ventilation process with position changes. Moreover, extra fat deposition in the ribcage and abdominal area elongates the diaphragmatic and abdominal muscles and consequently affects the respiratory muscle function and contraction $[15,31]$. Low gravity compression in sitting position played a role in increasing chest wall compliance and decreasing resistance to the diaphragmatic contraction due to the weight of the abdominal content [32,33].

We had observed significantly negative correlations between the anthropometric measurements on one hand and all the evaluated spirometric parameters on the other hand. These results are in accordance with those of Feng et al. [34], who reported a correlation between lung function parameter and WHR, but this study was carried out in Chinese children and adolescents in the sitting position only. To the best of our knowledge, there were no comparable studies regarding the correlation between anthropometric and spirometric parameters in supine position in adult subjects.

The results of the current study have important implications. We have observed that even in the control group, all measured spirometric parameters had a statistically significant reduction with supine position. This should alarm us for the bad sequelae of overweight, even before reaching the stage of obesity. These findings support those of Peralta et al. [21] that moderate and high weight gains are associated with accelerated lung function decline, while weight loss is related to its attenuation. Our results could have significant implications in the management of critically ill patients, particularly those who are mechanically ventilated, and those who had impaired lung functions due to respiratory disorders $[4,35]$.

Finally, our findings could have implications in the era of the recent epidemic of COVID-19. Recently, the CDC announced that adults of any age with certain underlying medical conditions are at increased risk for severe illness from the virus that causes COVID19 (defined as hospitalization, admission to the ICU, intubation or mechanical ventilation, or death). One of these underlying conditions is obesity [36].

Despite that the current study is a prospective one with noninvasive simple procedures, it is not without limitations. These limitations include small sample size, females were not included, and a complete panel of pulmonary function tests (e.g., lung volumes, respiratory muscle strength) was not carried out. Further studies including larger sample size and female subjects with the implementation of comprehensive pulmonary function testing are warranted. 


\section{Conclusions}

Our study showed a strong relationship between central obesity and spirometric parameters among young Egyptian males. Individuals with central obesity had reduced spirometeric parameters in comparison to healthy ones. Change in position from sitting to supine has significant effects on spirometric parameters in both healthy middle age males with normal weight and those with overweight and central obesity. These results could have important clinical implications. Further studies are warranted.

\section{Acknowledgements}

The authors thank the technician team of the Department of Chest Diseases and Tuberculosis, Faculty of Medicine, Assiut University, for their great help in running the spirometric tests. We also thank Mr. Omar Sherif Mohamed, (omard114@gmail.com), the research co-ordinator, Department of Chest Diseases and Tuberculosis, Faculty of Medicine, Assiut University, for his great help in this manuscript.

\section{References}

1. World Health Organization. Obesity and overweight. Available from: https://www.who.int/news-room/fact-sheets/detail/obesity-and-overweight

2. Gregg EW, Shaw JE. Global health effects of overweight and obesity. N Engl J Med 2017;377:80-1.

3. Fang H, Berg E, Cheng X, Shen W. How to best assess abdominal obesity. Curr Opin Clin Nutr Metab Care 2018;21:360-5.

4. Kivimäki M, Kuosma E, Ferrie JE, Luukkonen R, Nyberg ST, Alfredsson L, et al. Overweight, obesity, and risk of cardiometabolic multimorbidity: pooled analysis of individuallevel data for 120813 adults from 16 cohort studies from the USA and Europe. Lancet Public Health 2017;2:e277-85.

5. Global BMI Mortality Collaboration, Di Angelantonio E, Bhupathiraju SN, Wormser D, Gao P, Kaptoge, S et al. Bodymass index and all-cause mortality: individual-participant-data meta-analysis of 239 prospective studies in four continents. Lancet 2016;388:776-86.

6. Sahakyan KR, Somers VK, Rodriguez-Escudero JP, Hodge DO, Carter RE, Sochor O, et al. Normal-weight central obesity: implications for total and cardiovascular mortality. Ann Intern Med 2015;163:827-35.

7. Dixon AE, Peters U. The effect of obesity on lung function. Expert Rev Respir Med 2018;12:755-767.

8. Sebo P, Herrmann FR, Haller DM. Accuracy of anthropometric measurements by general practitioners in overweight and obese patients. BMC Obes 2017;4:23.

9. Borruel S, Moltó JF, Alpanes M, Fernández-Durán E, ÁlvarezBlasco F, Luque-Ramírez M, et al. Surrogate markers of visceral adiposity in young adults: waist circumference and body mass index are more accurate than waist hip ratio, model of adipose distribution and visceral adiposity index. PLoS One 2014;9:e114112.

10. Zammit C, Liddicoat H, Moonsie I, Makker H. Obesity and respiratory diseases. Int J Gen Med 2010;3:335-43.

11. Parameswaran K, Todd DC, Soth M. Altered respiratory physiology in obesity. Can Respir J 2006;13:203-10.

12. Salome CM, King GG, Berend N. Physiology of obesity and effects on lung function. J Appl Physiol (1985) 2010;108:20611.
13. Dattani RS, Swerner CB, Stradling JR, Manuel ARG. Exploratory study into the effect of abdominal mass loading on airways resistance and ventilatory failure. BMJ Open Respir Res 2016;3:e00138. doi:

14. Mafort TT, Rufino R, Costa CH, Lopes AJ. Obesity: systemic and pulmonary complications, biochemical abnormalities, and impairment of lung function. Multidiscip Respir Med 2016;11:28.

15. Sonpeayung R, Tantisuwat A, Janwantanakul $P$, Thaveeratitham P. Total and compartmental chest wall volumes, lung function, and respiratory muscle strength in individuals with abdominal obesity: Effects of body positions. J Obes 2019;2019:9539846.

16. Sonpeayung R, Tantisuwat A, Klinsophon T, Thaveeratitham P. Which body position is the best for chest wall motion in healthy adults? A meta-analysis. Respir Care 2018;63:143951.

17. Al Lawati RI, Al Atbi AH. Changes in spirometry parameters with the change in posture from sitting to supine positions in asymptomatic normal weight, overweight and obese young Omani males. Iraq Med J 2018;2:64-7.

18. Katz S, Arish N, Rokach A, Zaltzman Y, Marcus EL. The effect of body position on pulmonary function: a systematic review. BMC Pulm Med 2018;18:159.

19. Nielsen KG, Holte K, Kehlet H. Effects of posture on postoperative pulmonary function. Acta Anaesthesiol Scand 2003;47:1270-5.

20. Romei M, Mauro LA, D'Angelo MG, Turconi AC, Bresolin N, Pedotti A, et al. Effects of gender and posture on thoracoabdominal kinematics during quiet breathing in healthy adults. Respir Physiol Neurobiol 2010;172:184-91.

21. Peralta GP, Marcon A, Carsin AE, Abramson MJ, Accordini S, Fs Amaral A, et al. Body mass index and weight change are associated with adult lung function trajectories: the prospective ECRHS study. Thorax 2020;75 313-20.

22. Centers for Disease Control and Prevention (CDC). Defining adult overweight and obesity. Available from: https://www.cdc.gov/obesity/adult/index.html

23. Alberti KG Zimmet PZ. Definition, diagnosis and classification of diabetes mellitus and its complications. Part 1: diagnosis and classification of diabetes mellitus. Provisional report of a WHO consultation. Diabet Med 1998;15:539-53.

24. Bacopoulou F, Efthymiou V, Landis G, Rentoumis A, Chrousos GP. Waist circumference, waist-to-hip ratio and waist-to-height ratio reference percentiles for abdominal obesity among Greek adolescents. BMC Pediatrics 2015;15:50.

25. Alberti KGMM, Zimmet P, Shaw J. Metabolic syndrome - a new world-wide definition. A consensus statement from the international diabetes federation. Diabet Med 2006;23:469-80.

26. World Health Organization. Waist circumference and waist-hip ratio: report of a WHO expert consultation. Geneva, 8-11 December 2008. Available from: https://www.who.int/publications/i/item/9789241501491

27. Graham BL, Steenbruggen I, Miller MR, Barjaktarevic IZ, Cooper BG, Hallet GL, et al. Standardization of spirometry 2019 update. An official American thoracic society and European respiratory society technical statement. Am J Respir Crit Care Med 2019;200:e70-88.

28. Pavana, Bhavya Shree P. Correlation of obesity and peak expiratory flow rate in young adult females. Ind J Physiother Occup Ther 2020;14:2.

29. Patel AK, Thakar HM. Spirometric values in sitting, standing and supine position. J Lung Pulm Respir Res 2015;2:1-3.

30. Vilke GM, Chan TC, Neuman T, Clausen JL. Spirometry in normal subjects in sitting, prone, and supine positions. Respir Care 2000;45:407-10. 
31. Magnani KL, Cataneo AJM. Respiratory muscle strength in obese individuals and influence of upper-body fat distribution. Sao Paulo Med J 2007;125:215-9.

32. Chlif M, Keochkerian D, Choquet D, Vaidie A, Ahmaidi S. Effects of obesity on breathing pattern, ventilatory neural drive and mechanics. Respir Physiol Neurobiol 2009;168:198-202.

33. Steier J, Lunt A, Hart N, Polkey MI, Moxham J. Observational study of the effect of obesity on lung volumes. Thorax 2014;69:752-9.

34. Feng K, Chen L, Han SM, Zhu GJ. Ratio of waist circumference to chest circumference is inversely associated with lung function in Chinese children and adolescents. Respirology 2012;17:1114-8.

35. Abdelaleem NA, Mohamed SAA, Abd ElHafeez AS, Bayoumi HA. Value of modified Burns Wean Assessment Program scores in the respiratory intensive care unit: an Egyptian study. Multidiscip Respir Med 2020;15:691.

36. Centers for Disease Control and Prevention (CDC). COVID19 (Coronavirus disease); People with certain medical conditions. Available from: https:/www.cdc.gov/coronavirus/2019ncov/need-extra-precautions/people-with-medical-conditions.html 